\title{
SKIRTINGO MEISTRIŠKUMO AEROBININKIŲ ANAEROBINIS PAJĖGUMAS MINANT VELOERGOMETRĄ
}

\author{
Arvydas Stasiulis, Kristina Zaičenkovienė, Roma Aleksandravičienė \\ Lietuvos kūno kultūros akademija, Kaunas, Lietuva
}

\begin{abstract}
Arvydas Stasiulis. Profesorius biomedicinos mokslų daktaras. Lietuvos kūno kultūros akademijos Prorektorius mokslo reikalams. Moksliniu tyrimų kryptis - aerobinio pajẻgumo greitoji ir lètoji adaptacija dèl treniruotès, laboratorinių krūvių poveikio.
\end{abstract}

\section{SANTRAUKA}

Sportine aerobika yra viena iš naujausiu gimnastikos sporto šaku, kuriq kultivuodami sportininkai pagal muzika turi atlikti didelio intensyvumo pagrindinius aerobikos judesius ir jungti juos su jëgos, šuoliu, lankstumo, pusiausvyros pratimais. Kaip ir kitos gimnastikos rūšys, sportinè aerobika reikalauja aerobinès ir anaerobinès ištvermès, šoklumo, lankstumo, jègos ir puikios koordinacijos. Visos šios fizinès ypatybès turi būti rodomos varžybinio pratimo metu (vidutine trukmé - $2 \mathrm{~min}$ ), atliekant koordinaciškai sudètingus judesius bei uvvairaus sudètingumo elementus dideliu intensyvumu be poilsio intervalu (Sports Aerobics Code of Points, 2002). Fiziologinius pokyčius specifinio fizinio krūvio (varžybinès veiklos) metu tyrè ispanu mokslininkai (Rodriguez et al., 1998). R. Aleksandravičiené (2005) ištyré skirtingo meistriškumo aerobininkiu aerobini pajëguma ir energijos sqnaudas varžybinès veiklos metu.

Tyrimo tikslas - nustatyti skirtingo meistriškumo aerobininkiu anaerobini pajèguma minant veloergometrq. Buvo tiriama 18 aerobikos sportininkių. Išanalizavus varžybiniu pratimu sudètinguma ir varžybu rezultatus, jos buvo suskirstytos i didesnio ir mažesnio sportinio meistriškumo grupes. Visos tiriamosios atliko 30 sekundžiu maksimalu Vingeito testa „Monark“ veloergometru. Testo ir atsigavimo po jo metu buvo registruojamas širdies susitraukimu dažnis naudojant „Polar" pulso matuokli S-810 (Suomija). Kapiliarinio kraujo méginiai buvo imami atsigavimo metu po Vingeito testo praejus 5 ir 20 minučiu kraujo laktato (La) koncentracijai nustatyti.

ŠSD isidirbimo greitis Vingeito testo metu buvo geresnis didesnio meistriškumo grupeje, nors rodikliu skirtumas tarp grupiu nebuvo statistiškai reikšmingas. ŠSD atsigavimo greičio rodikliai po Vingeito testo panašūs abiejose grupèse $(p>0,05)$. Maksimali laktato koncentracija kraujyje ir laktato sumažéjimo greitis po Vingeito testo taip pat buvo panašūs. Didesnę maksimalia galia Vingeito testo pradžioje pasiekè mažesnio meistriškumo aerobininkès (atitinkamai $7,76(0,62)$ ir 7,579 (0,9) W/ kg mažesnio ir didesnio meistriškumo grupèse), o galios sumažejimas buvo didesnis mažesnio meistriškumo grupeje, nors skirtumas nebuvo statistiškai reikšmingas. Abieju grupiu sportininkiu didžiausio mynimo dažnumo rodikliai buvo panašūs.

Rezultatai rodo, kad skirtingo meistriškumo aerobininkiu ŠSD kaita Vingeito testo metu nesiskiria. Pastebima mažesnio anaerobinio galingumo, bet didesnès anaerobinès ištvermès (atliekant $30 \mathrm{~s}$ Vingeito testa) tendencija didelio meistriškumo aerobininkiu grupeje. Nustatytas didelis individualiu anaerobinio pajègumo rodikliu skirtumas tarp visu tiriamuju grupiu.

Raktažodžiai: sportine aerobika, anaerobinis pajègumas, Vingeito testas, širdies susitraukimu dažnis.

\section{IVADAS}

$\mathrm{S}$ portinei aerobikai būdinga intensyvi varžybinè veikla, trunkanti nepilnas 2 minutes. Toks darbas apkrauna daugeli kūno raumenų, lavina aerobini ir anaerobini organizmo pajègumą. Sportinès aerobikos varžybų ir pratybų metu pastebimi beveik maksimalūs vegetacinių sistemų rodikliu pokyčiai, apkraunamos tiek aerobinès, tiek ir anaerobinès raumenu ATP resintezès sistemos (Rodriguez et al., 1998; Aleksandravičienė, 2005). Nustatyta, kad aerobininkès yra vidutinio aerobinio pajègumo, vertinant sunkinamo laipiojimo krūvio ar bėgtakio testo duomenis (Aleksandravičienè, 2005; Aleksandravičienè, Stasiulis, 2005).

Vienas iš populiariausių ir prieinamiausių testų anaerobiniam pajëgumui nustatyti -30 sekundžiu maksimalus Vingeito testas veloergometru (Inbar et al., 1996). Tarp daugybès įvairių šakų sportininkių tyrimų neaptikome darbų, analizuojančių aerobikos sportininkių anaerobini pajègumą taikant ši testą.

Tyrimo tikslas - nustatyti skirtingo meistriškumo aerobininkių anaerobini pajègumą minant veloergometrą. 


\section{TYRIMO METODAI}

Tiriamosios. Buvo tiriama 18 skirtingo meistriškumo aerobikos sportininkių, kurios pagal varžybinių pratimų sudètingumą ir varžybų rezultatus suskirstytos į dvi grupes: didesnio (D) ir mažesnio (M) meistriškumo. Tiriamuju antropometriniai duomenys ir amžius pateikti 1 lentelèje.

Vingeito testas. Testavimo dieną tiriamosios nesportavo, o išvakarèse galejo atlikti tik nesunku fizini krūvị. Tiriamujų anaerobini pajègumą nustatème Vingeito testu (Bar-Or, 1987). Buvo testuojama Monark 834 E veloergometru, leidžiančiu matuoti darbo galią ir mynimo dažnumą viso testo metu ( $5 \mathrm{~s}$ intervalais). Tiriamosios, sėdėdamos ant veloergometro, maksimaliomis pastangomis ji myne 30 sekundžių. Viso testo metu jos buvo skatinamos palaikyti kuo didesni mynimo dažnumą. Buvo parinktas individualus mechaninis veloergometro pasipriešinimas kiekvienai tiriamajai ir sudare 7,5\% jos kūno masès. Prieš tai buvo atliekama 5 minučių pramankšta, kurios metu tiriamosios mynè veloergometrą tolygiai $50-75 \mathrm{~W}$ galingumu ir atliko keletą labai trumpu greitejjimų. Tarp pramankštos ir 30 sekundžiu testo maksimaliu pajėgumu tiriamosios vieną minutę ilsèjosi. Baigus testą speciali kompiuterio programa pateikè duomenų išklotinę ir galios mažėjimo kreivę anaerobinio krūvio metu.

Laktato koncentracija kraujyje buvo nustatoma naudojant analizatoriu „Eksan-G“. Modifikuotas analizatorius (jame itaisyta membrana su fermentu laktato oksidaze) gali nustatyti 0,8 $25 \mathrm{mmol} / 1$ laktato koncentraciją (Kulis et al., 1988). Kapiliarinio kraujo mėginiai buvo imami iš piršto praejus 5 ir 20 minučiu po Vingeito testo.

ŠSD kaitos analizè. Per visą testavimo laiką ŠSD registruoti buvo naudojamas pulso matuoklis su atmintimi (Polar Accurex-Plus), kuris kas 5 sekundes fiksuodavo ŠSD reikšmes. ŠSD kaitos greitis Vingeito testo metu ir per pirmą minutę po jo buvo apskaičiuojamas ŠSD pokyti (tvinksniais) dalijant iš laiko (s).

Matematinè statistika. Buvo apskaičiuojami rodiklių aritmetiniai vidurkiai ir standartiniai nuokrypiai. Aritmetiniai vidurkiai palyginti naudojant neparametrini Kolmogorovo-Smirnovo testa, taikytą nepriklausomoms imtims. Statistinių hipotezių reikšmingumui patikrinti buvo pasirinktas patikimumo lygmuo $\mathrm{p}<0,05$. Visi apskaičiavimai atlikti naudojant programini paketą, ,Statistica for Windows“.

\section{REZULTATAI}

Palyginę ŠSD ịsidirbimo greitị Vingeito testo metu matome, kad pirmos grupès rodikliai yra didesni, negu antros, nors skirtumas tarp grupiu rodiklių nèra statistiškai reikšmingas (2 lent.). ŠSD atsigavimo greičiu po Vingeito testo rodikliai panašūs abiejose grupèse $(p>0,05)$. Maksimali laktato koncentracija kraujyje po Vingeito testo taip pat buvo panaši tarp abieju grupių tiriamujų. Laktato sumažejimo greitis po Vingeito testo buvo didesnis mažesnio meistriškumo grupeje, bet skirtumas statistiškai nereikšmingas.

Iš galios kitimo 30 sekundžių maksimalaus intensyvumo krūvio metu matyti (žr. pav.), kad per pirmas 5 sekundes didesnę galią pasiekè mažesnio meistriškumo grupès sportininkès. Priešingai, didesnio meistriškumo grupèje galios sumažèjimas buvo

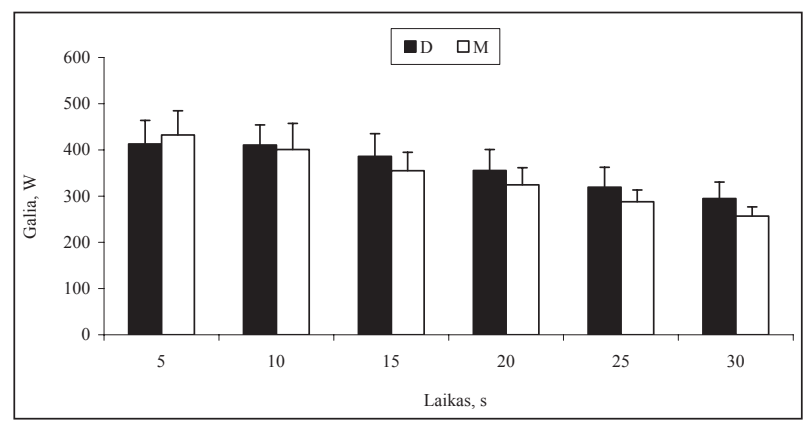

Pav. Didelio (D) ir mažo (M) meistriškumo aerobininkių galios kitimas Vingeito testo metu

\begin{tabular}{|c|c|c|c|}
\hline Tiriamujų skaičius & Amžius, $\mathrm{m}$. & Ūgis, $\mathrm{cm}$ & Svoris, $\mathrm{kg}$ \\
\hline 18 & $20,9(4,6)$ & $165,0(5,1)$ & $55,5(4,6)$ \\
\hline
\end{tabular}

\begin{tabular}{|l|c|c|}
\hline Rodikliai & Didelio meistriškumo $(\mathrm{n}=9)$ & Mažo meistriškumo $(\mathrm{n}=9)$ \\
\hline $\mathrm{La}_{\text {max }}, \mathrm{mmol} / \mathrm{l}$ & $6,49(0,85) 13,1$ & $6,78(0,91) 13,4$ \\
\hline $\mathrm{La}$ atsigavimo greitis, mmol / / min & $0,0377(0,0169) 44,8$ & $0,0393(0,0218) 55,4$ \\
\hline ŠSD issidirbimo greitis, tv. / s & $2,86(1,46) 51,0$ & $1,93(0,43) 22,3$ \\
\hline ŠSD atsigavimo greitis, tv. / s & $0,43(0,19) 44,2$ & $0,44(0,16) 36,4$ \\
\hline Didžiausia galia, W / kg & $7,579(0,9) 11,8$ & $7,76(0,62) 8,0$ \\
\hline Galios sumažèjimas, W / s & $3,93(1,94) 49,4$ & $5,32(1,91) 35,9$ \\
\hline Didžiausias mynimo dažnis, k. / min & $145,5(19,7) 13,5$ & $142,6(12,2) 8,6$ \\
\hline
\end{tabular}

1 lentelè. Tiriamųjų amžius ir antropometriniai duomenys (aritmetinis vidurkis ir standartiniai nuokrypiai)

2 lentelè. Skirtingo meistriškumo aerobininkių ŠSD, laktato koncentracijos ir darbo galios rodikliai (vidurkiai, (standartiniai nuokrypiai) ir variacijos koeficientai) Vingeito testo ir atsigavimo po jo metu Pastaba. $\mathrm{La}_{\max }$ - kraujo laktato koncentracija praejjus 5 minutèms po testo; La atsigavimo greitis kraujo laktato koncentracijos sumažéjimo greitis 5-20 atsigavimo minutę. 
mažesnis, negu mažesnio meistriškumo grupejje. Abiem atvejais skirtumas taip pat nepasieke statistiškai reikšmingo lygmens. Abiejų grupių didžiausio mynimo dažnumo rodikliai panašūs (2 lent.).

Pažymėtina, kad ŠSD kaitos, maksimalios laktato koncentracijos ir galios kitimo Vingeito testo metu rodiklių sklaida didelè. Minètų rodikliu variacijos koeficientai siekia net 50\% (2 lent.).

\section{REZULTATŲ APTARIMAS}

Šiuo tyrimu nustatème, kad nepaisant ryškaus individualių rodiklių skirtumo didesnio meistriškumo aerobininkiu ŠSD kaita greitesnė darbo metu ir šiek tiek mažesni anaerobinio galingumo, bet geresni anaerobinès ištvermès rodikliai.

Vingeito testo duomenys rodo, kad didesnio meistriškumo aerobininkès yra mažesnio anaerobinio pajègumo, bet atsparesnès nuovargiui maksimalaus intensyvumo veloergometrinio krūvio metu. Tai iš dalies gali priklausyti nuo geresnio aerobinio šios grupès sportininkių pajègumo, kadangi apie $50 \%$ energijos tokio testo metu vis dèlto gaunama aerobiniu būdu (Inbar et al., 1996). Tai, kad anaerobiniu procesų indèlis maksimalaus testo metu buvo panašus mūsų tirtose grupèse, rodo ir beveik vienoda laktato koncentracija 5 minutes po testo, panašus laktato sumažejjimo greitis atsigavimo laikotarpiu. Tyrimo metu nustatytos aerobininkių maksimalios galios reikšmès $(7,56-7,76 \mathrm{~W} / \mathrm{kg})$ yra didesnès už literatūroje pateikiamas nesportuojančių jaunų merginų tas pačias reikšmes - 5,8 W/ kg (Simoneau et al., 1983), bet mažesnès už greitojo čiuožimo sportininkiu $-8,6 \mathrm{~W} / \mathrm{kg}$ (Serresse, Simoneau et al., 1989) ar orientacininkių moteru $-8,1 \pm 1,5 \mathrm{~W} / \mathrm{kg}$ (Mockus ir kt., 2000). Šiu autorių tyrimo duomenimis, maksimali laktato koncentracija moteru grupejje buvo $6,3 \pm 1,4 \mathrm{mmol} / 1$, t. y. labai panaši kaip ir mūsų tirtu aerobininkių. Neseniai publikuoto tyrimo duomenimis, didelio meistriškumo gimnasčiu maksimali galia Vingeito testo metu siekia net $10-12 \mathrm{~W} / \mathrm{kg}$ (Lange et al., 2005). Taigi mūsų tirtu aerobininkių anaerobini pajègumą galima vertinti kaip vidutini, kuris nedaug atsilieka nuo ištvermès šakų sportininkių.
Svarbiu aerobinio pajègumo ir širdies bei kraujagysliu sistemos adaptacijos galimybiu rodikliu laikoma ir ŠSD kaita darbo bei atsigavimo metu (Jones, Carter, 2000). Tiesa, jo ryšys su ištvermès sportininkų varžybiniais rezultatais dar ne visiškai aiškus. Yra duomenu, kad geresni aerobini pajègumą turinčių asmenų ŠSD kaita darbo ir atsigavimo metu yra greitesnè (Imai et al., 1994). Tyrimai parodé, kad ŠSD po darbo greičiau sumažèja tų asmenų, kurių aerobinis darbingumas geresnis (Goldberg, Shephard, 1980). Ištyrus skirtingo fizinio parengtumo asmenis nustatyta, kad ìsidirbimo pradžioje (ŠSD padidejja 20\%) skirtumo tarp i̇vairaus treniruotumo grupių rodiklių nèra, bet ŠSD padidejus $40,60,80$ ir $100 \%$, treniruotu asmenu organizmas adaptuojasi greičiau (Taylor et al., 1999). Manoma, kad tai susiję su didesniu parasimpatinès nervų sistemos poveikiu sportininkų širdies veiklai (Pierpoint et al., 2000). Šio tyrimo metu nepastebèta ryškaus ŠSD kaitos skirtumo tarp skirtingo meistriškumo aerobininkių, nors matyti, kad didesnio meistriškumo grupejje buvo greitesne ŠSD kaita 30 sekundžių Vingeito testo metu.

Galima manyti, kad varžybini sportinès aerobikos rezultatą lemia daugybẻ veiksnių, tarp kurių aerobinis ir anaerobinis pajègumas turi tik vidutinišką reikšmę. Mūsų tyrimai gal tik parodo didesnę ištvermès svarbą aerobininkių meistriškumui, nors tai gali būti susiję ir su nevienodu skirtingo meistriškumo aerobininkių treniruotès krūviu.

\section{IŠVADOS}

1. Skirtingo meistriškumo aerobininkių anaerobinio pajègumo rodikliai, ŠSD ir laktato kaita Vingeito testo ir atsigavimo po jo metu statistiškai reikšmingai nesiskiria. Pastebima tendencija, kad didesnio meistriškumo aerobininkès yra mažesnio anaerobinio pajëgumo, bet didesni ju anaerobinès ištvermès rodikliai.

2. Nepriklausomai nuo aerobininkių meistriškumo pastebètas didelis individualių anaerobinio pajègumo, ypač anaerobinès ištvermès ir ŠSD kaitos, rodiklių skirtumas.

\section{LITERATŪRA}

Aleksandravičienè, R. (2005). Skirtingo amžiaus ir treniruotumo moteru fiziologiniai pokyčiai ir energetika aerobikos pratimu metu: daktaro disertacija. Kaunas: LKKA.

Aleksandravičienė, R., Stasiulis, A. (2005). Physiological responses during competitive sports aerobic exercise. Ugdymas. Küno kultūra. Sportas, 3 (57), 4-8.

Bar-Or, O. (1987). The Wingate Anaerobic Test — an update on methodology, reliability and validity. Sports Medicine, 4, 381-394.

Goldberg, D., Shephard, R. (1980). Stroke volume during recovery from upright bicycle exercise. Journal of Applied Physiology, 5, 33-37.

Imai, K., Sato, H., Hori, M., Kusuoka, H., Ozaki, H. et al. (1994). Vagally mediated heart rate recovery after exer- 
cise is accelerated in athletes but blunted in patients with chronic heart failure. Journal of the American College of Cardiology, 24, 1529-1535.

Inbar, O., Bar-Or, O., Skinner, J. (1996). The Wingate anaerobic test. Human Kinetics.

Jones, A. M., Carter, H. (2000). The effect of endurance training on parameters of aerobic fitness. Sports Medicine, 29 (6), 373-386.

Kulis, Y. Y., Laurinavichyus, V. S. A., Firantas, S. G. A. \& Kurtinaitiene, B. S. (1988). Determination of lactic acid with an Exan-G analyser. Journal of Analytical Chemistry of the USSR, 43 (7), 1521-1523.

Lange, B., Halkin, A., Bury, T. (2005). Physiological requirements of high level gymnastics. Revue Medicale de Liege, 939-945.

Mockus, P., Stasiulis, A., Alekrinskis, A. (2000). Didelio meistriškumo Lietuvos orientacininkų anaerobinis pajègumas. Sporto mokslas, 1 (19), 53-55.

Pierpoint, G., Stolpman, D., Gornick, C. (2000). Heart rate recovery post-exercise as an index of parasympathetic activity. Journal of the Autonomic Nervous System, 80, 16-174.

Rodriguez, F., Iglesias, X., Marina, M., Fado, C. (1998). Physiological demands of elite competitive aerobics. Journal of Sports Science, 16, 510-511.

Serrese, O, Ama, P., Simoneau, J. (1989). Anaerobic performances of sedentary and trained subjects. Canadian Journal of Sport Science, 14 (1), 46-52.

Simoneau, J., Lortie, G., Baulay, M., Bauchard, C. (1983). Tests of anaerobic alctatacid and lactacid capacities, description and reliability. Canadian Journal of Applied Sport Sciences, 2, 266-270.

Sports Aerobics Code of Points 2001-2004. (2002). Updated $26^{\text {th }}$ July 2002. Federation Internationale de Gymnastique.

Taylor, A., Osborne, M., Bube, L., Stocks, M. (1999). Cardiorespiratory dynamics: sensitivity of the on - transition to endurance - training status. European Journal of Applied Physiology, 80, 505-507.

\title{
ANAEROBIC PERFORMANCE DURING CYCLING ERGOMETRY IN WOMEN'S SPORTS AEROBICS ATHLETES WITH DIFFERENT LEVEL OF TRAINING
}

\author{
Arvydas Stasiulis, Kristina Zaičenkovienė, Roma Aleksandravičienė \\ Lithuanian Academy of Physical Education, Kaunas, Lithuania
}

\begin{abstract}
Aerobic gymnastics is one of the newest branches in gymnastics sport, when athletes must perform continuous complex and high intensity movement patterns to music, which originate from traditional aerobic steps and strength, flexibility and balance exercises. Aerobic gymnastics is characterized as an intensive physical exercise in which a number of muscle groups are actively engaged as well as both aerobic and anaerobic capacity of the body is developed. In competitive activities (lasting $2 \mathrm{~min}$ on average) physical properties, such as strength, flexibility, coordination must be demonstrated without rest intervals (Sports Aerobics Code of Points, 2002).

Physiological responses during a competitive exercise in aerobic gymnastics were determined by Spanish scientists (Rodriguez et al., 1998), aerobic capacity and energy expenditure of aerobic gymnastics athletes of different level of training during competitive exercise were studied by R. Aleksandravičienè (2005).

The aim of this study was to determine the anaerobic performance during cycling ergometry in differently trained sports aerobics women athletes.

A group of Lithuanian aerobic competitors $(n=15)$ with different level of training were engaged as the subjects in this experiment. Their anaerobic performance was assessed by using $30 \mathrm{~s}$ Wingate anaerobic test. The heart rate (HR) dynamics during Wingate test and during recovery was evaluated as well. In addition, capillary blood samples were taken at 5th and 20th min of recovery after Wingate test for evaluation of blood lactate concentration.

HR dynamics during Wingate test was faster in HT group, but difference was not significant $(p>0.05)$. HR dynamics during recovery was similar in both groups. The blood lactate concentration after Wingate test did not differ between groups. The rate of lactate decrease during recovery was higher in MT group. The maximal power during Wingate test was higher in MT group (7.76 (0.62) and $7.579(0.9) \mathrm{W} / \mathrm{kg}$ in MT and WT groups, respectively), but the rate of fatigue was lower in WT group $(p>0.05)$. The maximal pedalling frequency was similar in both groups.

The results of this study showed that better trained athletes' group demonstrated the tendency of faster HR kinetics during maximal Wingate test. The well trained sports aerobics' athletes also demonstrated the tendency of lower initial power but better fatigue resistance during $30 \mathrm{~s}$ maximal anaerobic test. There were large individual differences of anaerobic performance indexes independent of training level.
\end{abstract}

Keywords: sports aerobics, anaerobic capacity, Wingate test, heart rate.

Gauta 2006 m. kovo 5 d.

Received on March 5, 2006

Priimta 2006 m. gegužès 25 d

Accepted on May 25, 2006
Arvydas Stasiulis

Lietuvos kūno kultūros akademija

(Lithuanian Academy of Physical Education)

Sporto g. 6, LT-44221 Kaunas

Lietuva (Lithuania)

Tel +370 37302623

E-mail a.stasiulis@lkka.1t 